\title{
The Natural Approach and Teacher Professional Development
}

\author{
Farouq Khalil
}

\begin{abstract}
The objective today is to refresh your memories with guiding principles from the natural approach and their impact on classroom performance. Consisting of four parts, part one proceeds on a question-answer format to arouse ideas, initiate discussions and focus attention on the principles of the approach. Part two: Having discussed relevant questions with the audience on April $28^{\text {th }}, 2014$ at the Language Centre of an-Najah University, we received the unanimous responses below with some minor disagreement from the participants due to likely inadequate linguistic insights, I am afraid. Part three suggests innovations and applications for classroom teaching and learning. Part four draws out related conclusions. The methodology used here has made use of the web, books on applied linguistics and personal experience. In addition, from that day on, the paper has been updated by including and arguing new related insights of Philosopher Grice.
\end{abstract}

Keywords--natural, communicative, learning, environment, Grice, Maxims

\section{INTRODUCTION}

Definition: Developed by Krashen and Terrel (1983), the natural approach depends on the communicative view of language in which particular emphasis is laid on language as a set of messages that can be understood. As can be realized, this approach is still momentous as it meets the basic purpose of using a language: communication. It is also based on the following principles which I like to satisfactorily call reminders or guiding principles as they create a lead.

\section{Part one and two: Relevant questions and responses}

1. Relevant Question: Are you aware of the difference between language acquisition and language learning? Language acquisition takes place in a natural environment and defined as an unconscious process developed through using language meaningfully. Learning, on the other hand, is defined as a conscious process or discovering rules about a language, e.,g., our learning environment. At this point, we (myself) jokingly claimed that more glucose was needed for this environment and the joke made sense as the

audience didn't oppose to the point and were in full agreement with the answers given to question one above.

2. Relevant question: How does conscious learning operate? It operates only as a monitor or editor that checks or repairs the output of what has been acquired. At this point, we remember the role of some teachers in our environment as checking and correcting. Attempting to answer this question, most audience found it interesting to look at the teacher's role and thus were agreeable to his/ her role as a monitor (sb checking and correcting in our nonnative conscious environment).

Najah National University
3. Relevant question: How are grammatical structures acquired? Grammatical structures are acquired in a predictable order such as the sequence for teaching parts of speech which should proceed in the following manner:

Articles, nouns, pronouns, adjectives, verbs, adverbs, conjunctions, prepositions and interjections.

Also, the sequence for teaching words and sentences. We almost got to a consensus on the acquisition of grammatical structures in the above highlighted order with minor opposition on which should be taught first, adjectives or verbs. In fact, according to the natural approach, vocabulary is of prime importance prior to syntactic structures. With regards to the vocabulary of sequencing, it was decided that words should be taught in the traditionally accepted word-order (S.V.O) or in a sequence typical of stories and listingorder: first, then, next, finally, etc. As for sentences, they should be put according to their kinds in order to make a paragraph with reference to (underlying relations) and flow (successive events or thoughts).

4. Relevant question: What is the best way to acquire language? People acquire language best from messages that are just slightly beyond their current competence. Practically, no disagreement ensued from audience to my proposition that learners acquire language best from messages not in their present competence to some extent. In fact, they accepted the pertinent argument illustrated through three real-life experiences below:

A. A hospital in Nablus: The nurse was asked for a diagnosis of a patient, the answer was an "infraction" for a "thrombosis". To me as a non-specialist, infraction in the sense of "thrombosis" was completely beyond my competence because the nurse did not put forward comprehensible input and therefore rendered the message communicatively incomprehensible against the basic principles of the natural approach. Thus, the experience remained on my mind and looked "infraction" up, with the result of not finding a matching definition to "thrombosis" or "stroke".

B. The underlined sick report diagnosis teaches you sth as it sounds beyond one's current competence/ability.

Acute lumbosacral radiculopathy caused by disc protrusion

The underlined refers to any disease of spinal nerve roots.

C. A poetically-oriented student approached me and asked me to edit a poem titled "be a smile" with this verse in it "If you don't low, you won't rise". The verb "low" (make a long deep sound of cows) was not within her competence when I asked her; She turned out to have meant "If you do not feel (get) low, you won't rise. So, the verb "low" typical of cows became part of her newly learned vocabulary after the discussion.

5. Relevant question: When is learning more efficient, when a learner is tense or relaxed? The learner's emotional state can act as a filter that impedes or blocks input necessary to acquisition.

Responding to the query if the learner's nervous emotional state would block the input needed for language acquisition, the answer was yes. That is, one of the participants immediately agreed that relaxation promotes learning and 
stress blocks it; the rest seemed to agree as they showed no opposition.

\section{Part Three:}

Innovations and applications of the Natural Approach in class

In addition to applying the five principles of the natural approach above, we'd like to point out that owing to a relationship existing between the natural approach and pragmatics, a teacher can seek the support of (1) total physical response approach and (2) Grice's conversational maxims.

1. TPR (Originally developed by James Asher, an American professor of psychology, in 1960s,) the total physical response depends on the theory that one's memory is reinforced by association with physical movement, which enhances understanding of particular basic terms. Showing real objects in class would be an example of using TPR to teach vocabulary in class. In this context of vocab teaching, a video clip via a computer's program or a power point slide on the use of culturally-oriented English vocabulary can also be introduced through dialogue/street interviews or fill-in-the gap to deepen understanding. In fact, the vocabulary items can further be expanded by referring to various related parts of speech. Thus, listening, speaking and reading will benefit, depending on how consciously /actively the listener/reader are listening/reading.

2. As a tool, a paradigm of synonyms, antonyms and word associations can be usefully used to explain and expand vocabulary in an interesting way. The following are a few examples in point:

$\begin{array}{ll}\text { Synonyms: } & \\ \text { Essential } & \text { rigorous } \\ \text { Vital } & \text { stringent } \\ \text { Crucial } & \text { Severe }\end{array}$

$\begin{array}{lll}\begin{array}{l}\text { Antonyms: } \\ \text { Profane } \\ \text { Sexual }\end{array} & \begin{array}{l}\text { improfane } \\ \text { asexual } \\ \text { asymmetrical } \\ \text { Merit }\end{array} & \\ \text { demerit } & \\ \text { Word associations: } & & \\ \text { Shout } & \text { shoot } & \\ \text { Sheep } & \text { cheap } & \\ \text { Rabbit } & \text { rapid } & \text { breed/bird } \\ \text { Bread } & & \text { obsolete } \\ \text { Absolute } & & \text { rule } \\ \text { Role } & & \text { shop } \\ \text { Chop } & & \text { throw } \\ \text { Through } & & \text { soap } \\ \text { Soup } & & \end{array}$

3. Grice's conversational maxims of logic (quantity_don't say too little or too much, quality be true and evidence aware, relation_stay on topic, manner_ avoid ambiguity and obsecurity_be clear, bebrief_up to point and be-orderly_be organized). (Grice, 1989: 26)

Logical as the above maxims sound, the researcher recommends that, from a practical viewpoint, learners should be trained on how to apply and benefit from these maxims in their outgoing thoughts, oral and written expression. The output would be more effective as well as efficient listener's understanding of the produced messages. To be more specific, my teaching practice always applies "the relation"and"Be-orderly", if not all, through the relevant tools mentioned earlier.

\section{Conclusions}

\section{Part Four:}

1. To be efficient, teachers are advised to:

a. Ensure their input to students is understandable. b. Teach what they think new knowledge to their students as it will be attention-getting.

2. Gricean maxims are good to observe in teaching and incentive to independent thinking.

3. TPR consolidates the natural approach as it works towards the goal of boosting comprehension and communication.

\section{REFERENCES}

[1] Brown, H.D (2000) Principles of Language Learning and Teaching $\left(4^{\text {th }} E d\right.$.). New York: Longman

[2] Grice, Herbert Paul (1989) Studies in the Way of Words. Mass, London: Harvard, Univ. Press

[3] Richards, J.C. and Rogers, T.S. (1986) Approaches and Methods in Language Teaching: A description and Analysis. Cambridge, UK: Cambridge University Press.

[4] Yule, George (1996) the Study of Language (sec. Ed.) UK: Cambridge Univ. Press

[5] En. Wikipedia.org/Wiki/Natural-Approach www2.Vobs. at/Ludescher/Alternative\%20 methods/Natural Approach.htm

[6] www.one stopenglish.com.games/ 